\title{
The Nerve Growth Factor: thirty-five years later
}

\author{
Rita Levi-Montalcini \\ Laboratory of Cell Biology, via Romagnosi 18A, Rome, Italy
}

\section{Introduction: Neurogenesis and its early experimental approach} 'Embryogenesis is in some way a model system. It has always been distinguished by the exactitude even puctilio, of its anatomical descriptions. An experiment by one of the great masters of embryology could be made the text of a discourse on scientific method. But something is wrong, or has been wrong. There is no theory of development in the sense in which Mendelism is a theory that accounts for the results of breeding experiments. There has therefore been little sense of progression or timeliness about embryological research. Of many papers delivered at embryological meetings, however good they may be in themselves...one too often feels that they might have been delivered five years beforehand without making anyone much the wiser or deferred for five years without making anyone conscious of a great loss' (1).

This feeling of frustration so incisively conveyed in these considerations by P.Medawar, pervaded, in the forties, the field of experimental embryology which had been enthusiastically acclaimed in the mid-thirties, when the upper lip of the amphibian blastopore brought this area of research to the forefront of the biological stage. The side branch of experimental neuroembryology, which had stemmed out from the common tree and was entirely devoted to the study of the trophic interrelations between neuronal cell populations and between these and the innervated organs and tissues was then in its initial vigorous growth phase. It in turn suffered from a sharp decrease in the enthusiasm that had inflamed the pioneers in this field, ever since R.G.Harrison delivered his celebrated lecture on this topic at the Royal Society in London in 1935 (2). Although the alternate 'wax and wane' cycles are the rule rather than the exception in all fields of human endeavor, in that of biological sciences the 'wane' is all too often indicative of a justified loss of faith in the rational and methodical approach that had at first raised so much hope.

A brief account of the state-of-the-art of experimental neuroembryology in the forties, when interest in this approach to the study of the developing nervous system was waning, is a prerequisite for understanding the sudden unforeseeable turn of events which resulted in the discovery of the Nerve Growth Factor.

\section{Experimental neuroembryology in the early forties}

The replacement, in 1934 by Viktor Hamburger, of the chick embryo with that of the amphibian larva as object of choice for the analysis of the effects of limb bud extirpation on spinal motor neurons and sensory nerve cells innervating the limbs (3), signed the beginning of a long series of investigations centered on the analysis of this and related experimental systems in avian embryos. Here I shall only list the major advantages offered by the chick embryo over amphibian larvae as a subject of neurological investigations.

The avian nervous system is built according to a more elaborate design than that of amphibians, and it lends itself to a more rigorous analysis of its nerve centers than that of lower vertebrates. Extensive fundamental studies on the nervous system of the chick embryo, with use of the invaluable silver specific techniques by Ramon y Cajal and coworkers, extended recently by myself and other investigators $(4,5)$, provided a very accurate blueprint of most nerve centers and their developmental history during neurogenesis. This allowed the detection of even small infractions to normal developmental rules, in experimentally manipulated embryos. At variance with ontogenetic processes in amphibians, in chick embryos the same processes unfold according to a rigidly scheduled time sequence which never departs from the anticipated. It is therefore possible to compare the central and peripheral nerve centers of experimental and control specimens, in embryos incubated under the same temperature and other environmental conditions. The analysis, in amphibian larvae, was extended to the brain, spinal cord and peripheral nervous system and various experimental situations. In the chick embryo, it was mainly confined to the study of the effects called forth by extirpation of limb primordia or implantation of additional wing or leg buds, on their innervating motor and sensory nerve centers. In 1934, Viktor Hamburger published an article (3) on the effects of wing bud extirpation on the development of the brachial spinal motor segment and sensory dorsal root ganglia innervating the wing. He came to the conclusion that the hypoplasia of motor nerve cells of the ventral horn and of other nerve cells of the same hemisection of the spinal cord, resulted from lack of stimuli centripetally transmitted by nerve fibers of the first differentiated neurons. These normally exert a regulatory effect on proliferation and differentiation of neighboring nerve cells. A re-investigation of the effects produced by limb bud extirpation, prospected a different control mechanism of the developing nerve centers by peripheral tissues. Through serial studies of silver-stained embryos, the conclusion reached was that the severe hypoplasia of nerve centers deprived of their fields of innervation, resulted from death of differentiated neurons and not from failure of recruitment of neurons from a pool of still uncommitted nerve cell precursors $(6,7)$. In 1947, Hamburger invited me to join him for the purpose of re-investigating this problem. This invitation marked the beginning of a thirty year period that I spent at Washington University, and of my lifelong friendship with Viktor, Our 1949 article (7) confirmed the hypothesis previously submitted by G.Levi and myself. The satisfaction of this confirmation of an important theoretical issue, and the successful analysis of other neuroembryological problems $(8,9)$ was, however, perturbed by the realization of the low resolution power of the techniques in our possession for in-depth exploration of the tremendously complex neurogenetic processes. The temptation to abandon the experimental analysis of the developing nervous system and move into the phage field, which was in full blossom in the forties, did, however, not take hold 
thanks to unpredictable and most fortunate events which occurred at the same time and opened a new era in developmental neurobiology.

\section{The unexpected break: a gift from malignant issues}

In a 1948 article, a former student of Viktor Hamburger, Elmer Bueker, reported the results of a bold and imaginative experiment consisting of the grafting of fragments of mouse sarcoma 180 into the body wall of 3-day chick embryos. The histological study of the embryos fixed 3-5 days later, showed that sensory nerve fibers emerging from adjacent dorsal root ganglia had gained access into the neoplastic tissue while no motor nerve fibers entered into the tumor (10). The author concluded that histochemical properties of the fast-growing mouse sarcoma offered a favorable field for growth of sensory fibers. This condition, in turn, resulted in a slight but consistent volume increase of these ganglia as compared with that of homologous ganglia innervating the wing of the contralateral side. Viktor and I re-investigated this remarkable phenomenon adopting the method I had developed during my first neuroembryological studies, i.e. that of a daily inspection of control and experimental embryos serially sectioned and impregnated with a specific silver technique. Our results confirmed those reported by Bueker, but at the same time uncovered other effects elicited by grafts of the mouse tumor, which hardly fit in with the hypothesis that they were in the same range and of the same nature as those called forth by transplants of normal embryonic tissues. They differed from the latter in the following, most significant, respects: sympathetic, not just sensory fibers, gained access into the neoplastic tissues where they built a network of extraordinarily high density; nerve fibers branched at random between tumoral cells without, however, establishing synaptic connections with them; sensory and sympathetic ganglia innervating the tumor underwent a progressive increase in volume, attaining, in the case of sympathetic ganglia, a size about six times larger than that of the same control ganglia (11). Subsequent experiments uncovered another astonishing deviation from the norm in embryos bearing transplants of mouse sarcoma 180 or of another tumor of identical origin, known as sarcoma 37. It was found that embryonic viscera which in normal specimens are devoid of innerviation, such as the mesonephroi, or which become scarcely innervated only in late developmental stages, such as the sex glands, the thyroid, the parathyroid and the spleen, were loaded with sympathetic nerve fibers at early embryonic stages (12). A patent infraction of all developmental rules, came to light with the discovery of thick sympathetic fiber bundles inside the veins of the host, where they protruded in the form of large neuromas obstructing blood circulation (Figure 1). All sympathetic chain ganglia, and not only ganglia adjacent to or in direct connection with neoplastic tissues, were enormously enlarged. The hypothesis that these anomalous effects could result from the release of a soluble, diffusible agent by neoplastic cells, which altered the differentiative and growth properties of its target cells, received full confirmation from experiments transplanting one or the other mouse sarcoma onto the chorio-allantoic membrane of 4-6-day chick embryos, in such a position as to prevent a direct contact between embryonic and neoplastic tissues (Figure 2). Embryonic and tumoral tissues were, however, in reciprocal connection through the circulatory system. The finding that these extra-embryonic transplants elicited the same effects as intra-embryonic grafts gave definite evidence for the diffusible nature of the tumoral nerve growth promoting factor $(12,13)$.

Attempts to replicate these effects by implanting dried tumor pellets or by injecting extract of either sarcoma were unsuccessful. I then thought of resorting to the tissue culture technique, which I had practiced with G.Levi at the University of Turin. Lack of facilities in this field in the Department of Zoology at Washington University, prompted me to request the hospitality of Professor Carlos Chagas, Director of the Biophysic Institute of the University of Brasil, Rio de Janeiro. There, a friend of mine, Hertha Meyer, had built and was director of a most efficient tissue culture unit. Upon approval and invitation by Professor Chagas, I board-
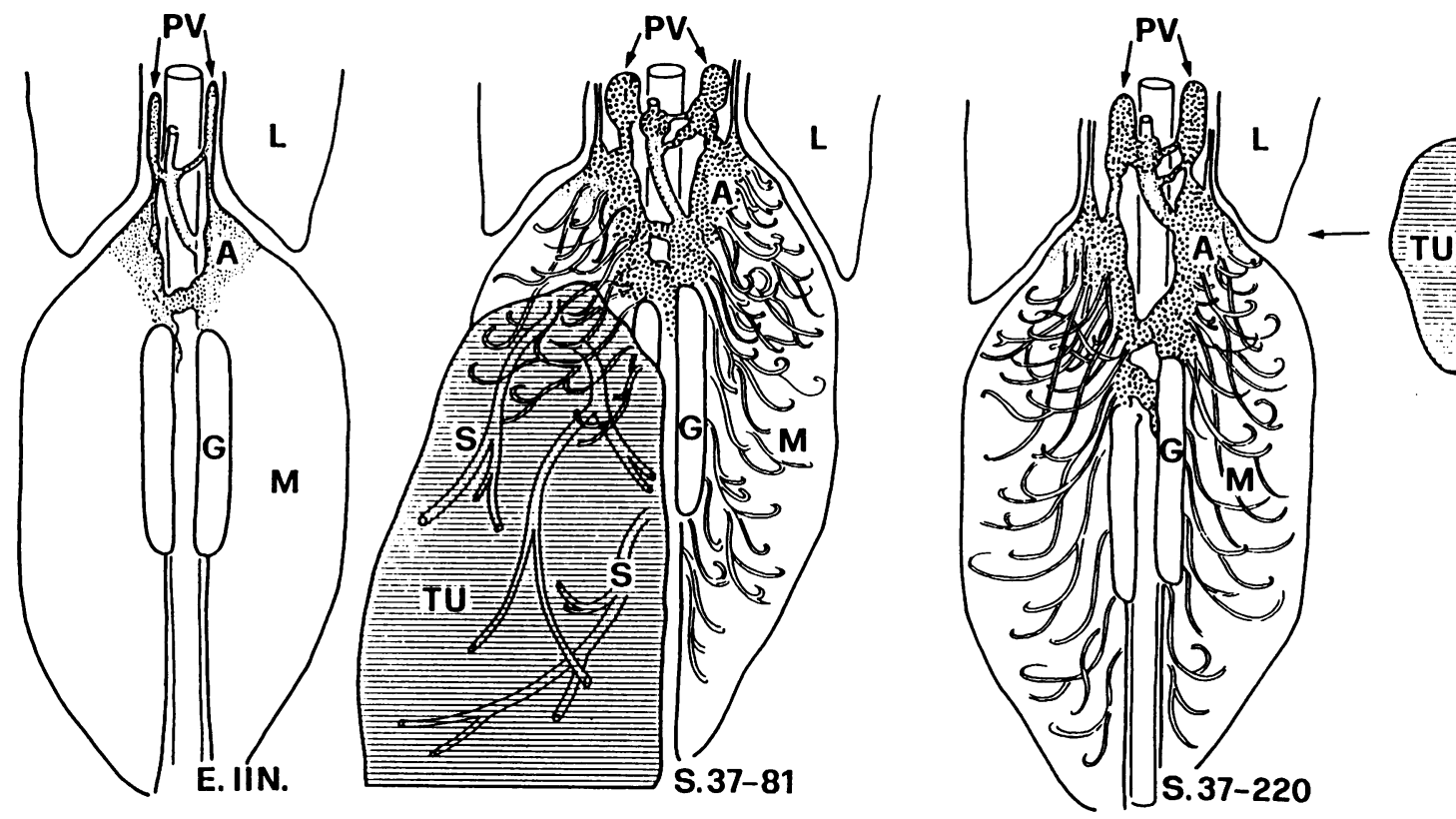

Fig. 1. Semi-diagrammatic reconstruction of a normal 11-day chick embryo (E lln), an 11-day embryo carrying an intra-embryonic transplant of mouse sarcoma (S 37-81) and an 11-day embryo with transplant of sarcoma 37 on the chorio-allantoic membrane (S 37-220). Note the hyperplastic growth of the prevertebral chain ganglia in embryos carrying tumor transplants. Visceral nerve fibers from these ganglia invade the nearby mesonephroi. A, adrenal; G, gonad; L, lung; M, mesonephros; PV, prevertebral ganglia; S, sensory nerves; Tu, tumor (from ref. 12). 
ed a plane for Rio de Janeiro, carrying two mice in my handbag bearing transplants of mouse sarcomas 180 and 37.

The Nerve Growth Factor at its early in-vitro and in-vivo debut 'The tumor had given a first hint of its existence in St. Louis but it was in Rio de Janeiro that it revealed itself, and it did so in a theatrical and grand way, as if spurred by the bright atmosphere of that explosive and exhuberant manifestation of life that is the Carnival in Rio' (14).

The discovery of the growth response elicited by a soluble tumoral agent revealed the receptivity of developing nerve cells to hitherto unknown humoral factors and in this way opened a new area of investigaton. The in-vitro bioassay too offered a practical and invaluable tool for uncovering the identity card of this factor and paved the way for the study of its mechanism of action. Ink drawings which I enclosed in several letters mailed from Rio to Viktor, give an eloquent account of the spectacular way in which this still unknown agent revealed itself. Sensory and sympathetic ganglia explanted from 8-day chick embryos in a semi-solid medium in proximity to but not in contact with fragments of mouse sarcoma 180 or 37 , produced, in a 24-h period, a halo of nerve fibers of maximal density on the side facing the tumor (15) (Figure 3). The euphoric state elicited by this discovery was dampened, however, shortly after by the discovery that normal mouse tissues, at variance with those of chick embryos, induce a milder (Figure 3a,b) but not substantially different effect from that of mouse sarcomas. In retrospect, this should have alerted us to a novel and even more significative

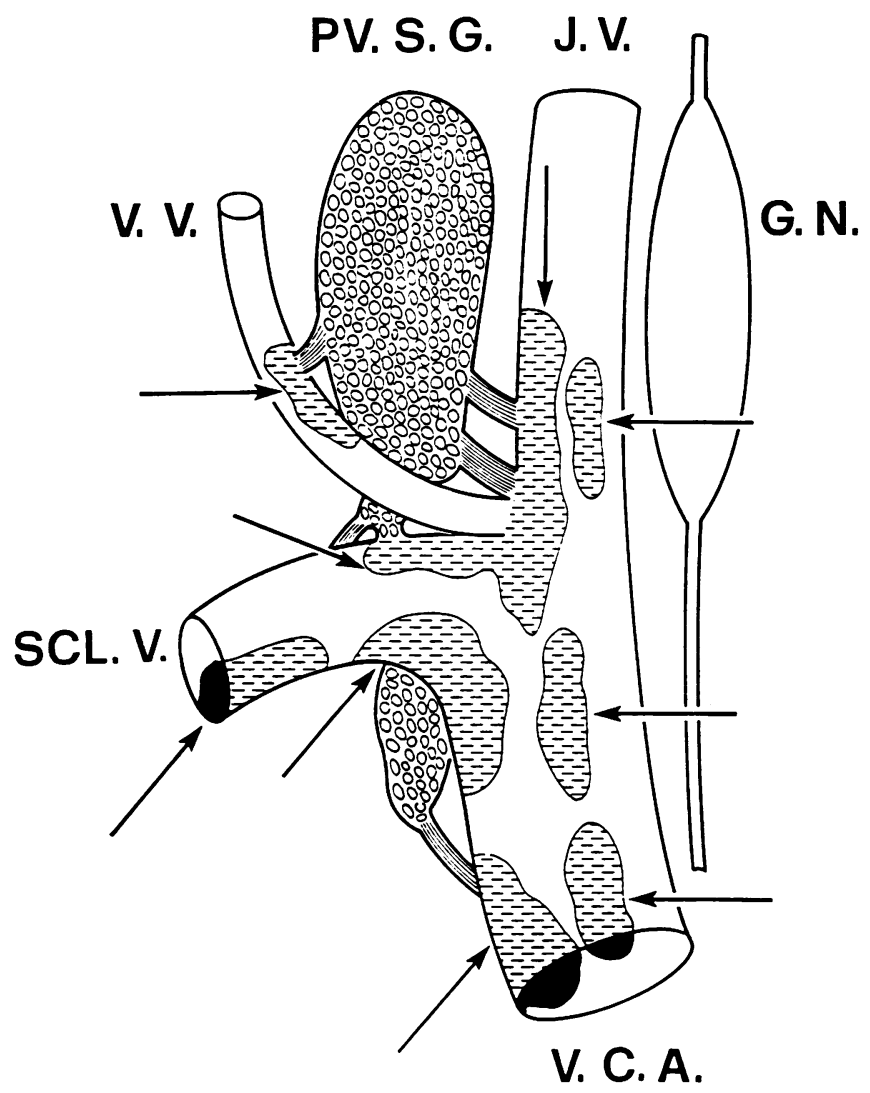

Fig. 2. Sixteen-day chick embryo with intra-embryonic tumor (sarcoma 180). Ingrowth of sympathetic nerve fibers into the jugular, vertebral, subclavian, anterior caval veins. GN, ganglium nodosum; JV, jugular vein; PV.SG, paravertebral sympathetic ganglion; SCL.V, subclavian vein; VCA, anterior caval vein; VV, vertebral vein. Arrows point to nerve agglomerations (from ref. 12). aspect of these in-vitro experiments; namely, the widespread presence of the factor endowed with nerve growth promoting activity in normal and neoplastic tissues. The failure to realize the significance of this 'mouse effect' was beneficial rather than detrimental, since for the next two years our attention was entirely focused on the study of the chemical nature of the factor released by the two mouse sarcomas in much larger quantities than from normal mouse tissues.

A young biochemist, Stanley Cohen, who joined our Group shortly before my return from Rio, isolated from the two tumors a nucleoprotein fraction endowed with the in-vitro nerve growth promoting activity (16). Chance, rather than calculated search, signed a new, most fortunate turn of events. In order to degrade the nucleic acids present in this active fraction, Stan made use of snake venom which contains, among other enzymes, the nucleic acid degrading enzyme, phosphodiesterase. Its addition in minute amounts to the nucleoprotein tumor fraction was expected to suppress the formation of the fibrillar halo if nucleic acids rather than the protein were responsible for the nerve growth promoting effect elicited by this fraction. The startling result was a marked increase in the density of the fibrillar halo around the
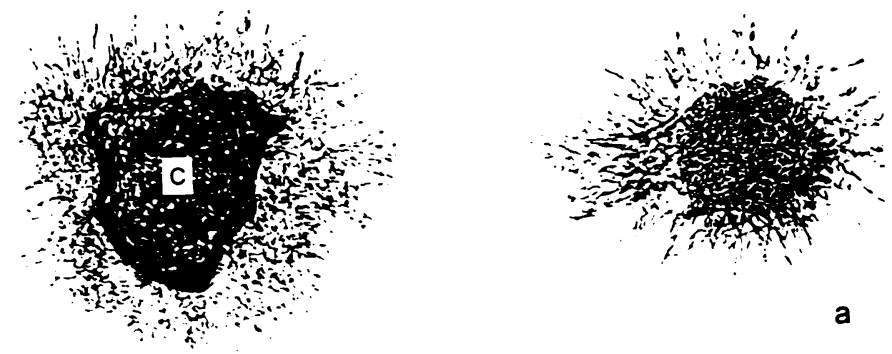

a

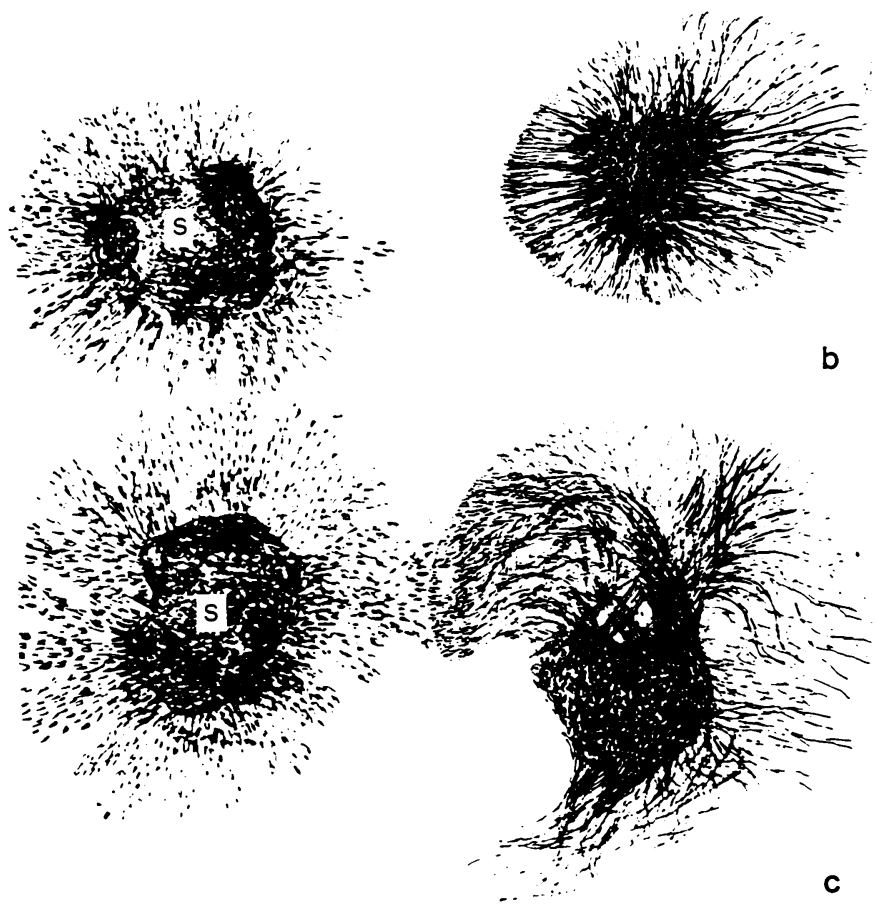

Fig. 3. Drawings illustrating the in-vitro 'halo' effect on 8-day chick embryo sensory ganglia cultured in the presence of fragments of mouse sarcoma 180 for $24 \mathrm{~h}$ (b) or $48 \mathrm{~h}$ (c). In (a) the ganglion, which faces a fragment of chick embryonic tissue, shows fibroblasts but few nerve fibers. In (b) and (c), the ganglia, facing fragments of sarcoma 180, show the typical 'halo' effect elicited by the growth factor released from the sarcoma. Note in (c) the first evidence of a neurotropic effect of the growth factor. 
ganglia incubated in the presence of the tumoral fraction treated with snake venom. Since a dense fibrillar halo was produced also around ganglia cultured in the presence of minute amounts of snake venom alone, it became apparent that the venom itself was a most potent source of nerve growth promoting activity. On the basis of biochemical studies, Cohen was in fact able to show that equivalent growth stimulation effects were obtained by $15000 \mu \mathrm{g}$ of a sarcoma 180 homogenate and $6 \mu \mathrm{g}$ of the moccasin snake venom. From the latter, after several purification steps, he isolated a non-dialyzable, heat-labile particle endowed with nerve growth promoting activity, identified in a protein molecule of mol. wt in the order of $20000(17,18)$. Microgram quantities of the purified snake venom fraction endowed with nerve growth promoting property, injected daily into the yolk of 6-8-day chick embryos for a 3-5-day period, resulted in the overgrowth of sensory and sympathetic ganglia and excessive production of their fibers. Sympathetic nerve bundles branched profusely into the viscera and protruded into the cavity of the veins, mimicking in all details the effects elicited by grafts of mouse sarcomas (19).

If chance brought to our attention the unforeseeable presence of two nerve growth promoting sources in mouse sarcomas and in snake venom, the subsequent findings that mouse submandibular salivary gland extract added in a minute quantity to the culture medium elicits an even denser and more compact fibrillar halo, was the result of a calculated search. These glands, as the homologue of the snake venom glands, were chosen by Stanley Cohen (20) to be more likely than other organs screened with the in-vitro bioassay, to store the nerve growth factor (NGF). These results were soon followed by purification and identification by Cohen of the salivary factor in a protein molecule of evaluated mol. wt of 44000 (20). Its availability in larger quantitites than the venom NGF, and its moderate toxicity when injected in a highly purified form, made the exploration of its biological activity in neonatal, young and adult mammals possible (21). The results of these investigations signed the beginning of an ever more extensive and systematic in-vivo and in-vitro analysis of the salivary NGF, of its chemical structure, mechanism and spectrum of action. Only the most significant findings reported from several laboratories in original and review articles will be considered in the following pages.

The vital role of NGF in the life of its target cells

In spite of, or perhaps because of, its most unusual and almost extravagant behavior in living organisms and in-vitro systems, NGF did not find enthusiastic reception by the scientific community at first, as was indicated by the reluctance of other investigators to engage in this line of research. The discovery of a protein molecule from such diverse and unrelated sources as mouse sarcomas, snake venom and mouse salivary glands, that elicited such a potent and disrupting action on normal neurogenetic processes, did not fit into any conceptual preexisting schemes, nor seem to bear any relationship to normal control mechanisms at work during ontogenesis. It was in this skeptical atmosphere that NGF asserted, in a most forceful way, its vital role in the life of its target cells. Previous in-vitro experiments had shown that incubation of snake venom with its antiserum inhibited the fiber outgrowth induced by the venom NGF. A specific antiserum to salivary NGF likewise abolished the formation of the in-vitro fibrillar halo. These results suggested testing the effect of daily injections of small amounts of this antiserum (AS-NGF) in neonatal rodents. The inspection of treated mice, performed at the end of the first month at the stereo and optic microscopes, revealed the near total disappearance of sympathetic para- and prevertebral chain ganglia $(22-24)$. This dramatic effect, which deprives newborn rodents and other neonatal mammals injected with antiserum to salivary NGF of the sympathetic system, without interfering with their normal development and vitality, became known as immunosympathectomy $(25,26)$. The same treatment produces much less damaging effects in young and adult animals.

Two alternative hypotheses were submitted to explain the mechanism underlying the destructive effects of the antiserum: (i) a complement-mediated cytotoxic effect, or (ii) the inactivation of NGF or of an NGF-like protein essential for differentiation and survival of sympathetic nerve cells. Although the first hypothesis was favored in early articles, the second progressively gained support and is now generally accepted on the basis of this and an in-vitro experimental approach which provided additional unequivocable evidence of the essential role NGF plays in the early differentiation stages of its target cells. The in-vitro experiments consisted of the dissociation of sensory and sympathetic nerve cells from ganglia of 8-11-day chick embryos and their incubation in minimum essential media. Nerve cells failed to survive unless nanogram quantities of NGF were added daily to the culture medium (27). The in-vitro evidence for the role of NGF in the early phases of development of sensory nerve cells, received confirmation from subsequent experiments which proved that administration of NGF antiserum to rodent fetuses $(28,29)$ and autoimmunization of pregnant rodents against endogenous NGF,

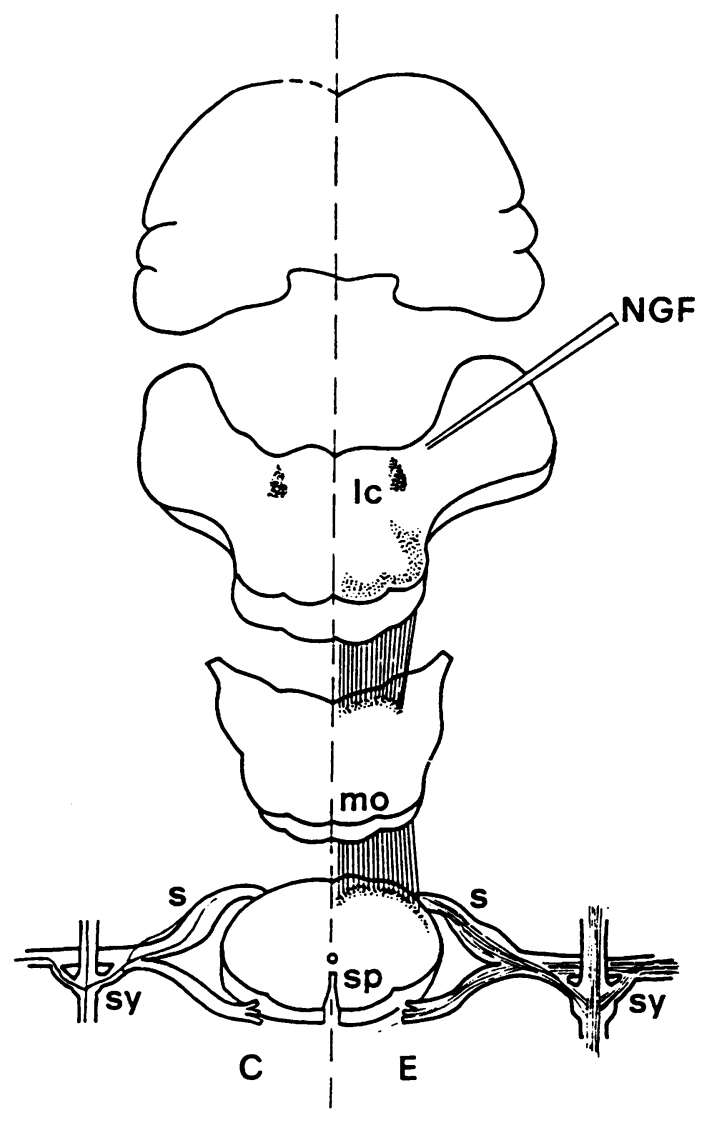

Fig. 4. Diagrammatic representation of sympathetic fiber bundles which enter the spinal cord and medulla oblongata from adjacent sympathetic ganglia in intracerebrally NGF-injected neonatal rats. Left half: control (C). Right half: experimental (E) case. NGF, site of injection of NGF into the floor of the fourth ventricle; lc, locus coeruleus; mo, medullar oblongata; sp, spinal cord; s, sensory ganglia; sy, sympathetic ganglia. Sympathetic fibers run across the sensory ganglion and enter into the neural tube with the dorsal roots (from ref. 40 ). 
result in failure of sensory ganglia to undergo normal development (30).

NGF as a retrograde trophic messenger and trophic factor

The evidence in favor of the hypothesis that immunosympathectomy results from removal, by AS-NGF (31), of circulating endogenous NGF, opened the questions of how NGF reached its target cells and what were its sources of production. Subsequent experimental pharmacological and surgical approaches provided satisfactory answers to both questions, and in view of the interest in these problems, techniques and main findings will be briefly reported.

Administration to neonatal rodents of drugs such as 6-hydroxydopamine which destroys adrenergic nerve endings (32) or of vinblastine which blocks axonal transport (33), results in death of the large majority of sympathetic nerve cells in their most active phase of differentiation and growth. The degenerative effects produced by these pharmacological components compare in magnitude with those produced in administration of AS-NGF and result in the destruction of para- and prevertebral sympathetic ganglia through a process which became known as chemical sympathectomy $(32,33)$. A third experimental manipulation, consisting of the surgical transectomy of postganglionic axons of superior cervical ganglion performed in neonatal rodents, results in the death of $\sim 90 \%$ of immature sympathetic cells in this ganglion (34). The experimental evidence that in all instances nerve cell death is prevented by supply of exogenous NGF $(30,35-37)$, demonstrates the vital role played by this molecule in the life and differentiation of these cells. The subsequent demonstration that labeled NGF is taken up by nerve endings of sympathetic (38) or sensory fibers (39) and is retrogradely transported to the cell perikarya, lent strong support to the concept of NGF as a trophic messenger, conveyed through nerve fibers from peripheral cells to the innervating neurons. Discon- nection of the partners by chemical or surgical axotomy, results in death of differentiating nerve cells deprived of this essential molecule.

At the same time as the vital role of NGF in developing sympathetic and sensory nerve cells was assessed and its retrograde transport from peripheral tissues was well documented, another important property of NGF - its ability to direct growing or regenerating axons of sensory and sympathetic fibers along its concentration gradient (neurotropism) - was definitely established through different in-vivo and in-vitro experimental approaches (40-45).

The first strong evidence for a NGF neurotropic effect was obtained from experiments of daily micro-injections of NGF into the floor of the fourth ventricle. A 7-day treatment resulted in the penetration of fiber bundles originating from sympathetic ganglia inside the neural tube and in their ending at the level of experimentally produced NGF pools $(40,41)$ (Figure 4). In-vitro experimental approaches gave more rigorous proof that neurites of NGF target cells grow along a NGF concentration gradient, and deflect their route according to the changed position of the NGF-releasing pipette (42). While these studies unequivocably establish the NGF neurotropic effect as independent from its trophic action, they leave unanswered the question of whether this effect is exerted through a local control of growth cone motility (43), altered adhesion of this locomotor organelle to the substratum $(44,45)$, or via other mechanism(s) $(46,47)$.

Neuronal and non-neuronal target cells

As indicated in Table I, targets of NGF action that have been well characterized up to now, can be classified under three main categories: (i) neural-crest derivatives; (ii) central nervous system (CNS) neurons; and (iii) cells of non-neuronal origin. For a thorough analysis of the many and diversified effects exerted by NGF on each one of these cells, the reader is referred to review

Table I. NGF target cells

NEURAL CREST DERIVATIVES
Sympathoadrenal

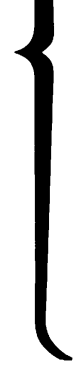

Sensory neurons

Cholinergic neurons

Adrenergic, indoleaminergic and peptidergic neurons

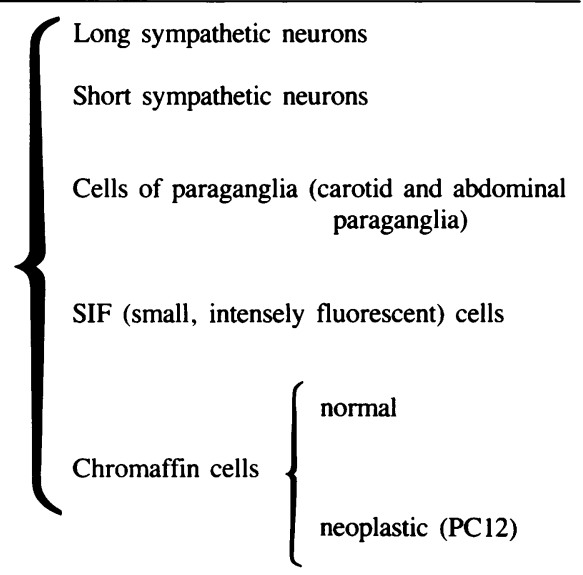

Corpus striatum, basal forebrain, septum, nucleus diagonal band of Broca

Xenopus laevis tadpoles 
articles on this specific matter (47-52). I wish to make in this context only some general considerations.

A generally valid rule is that all cells are maximally responsive to NGF action during their early differentiation; the response undergoes progressive restriction in the adult without, however, being totally effaced. Long sympathetic neurons and sensory neurons, with particular reference to those of the dorso-medial quadrant of spinal ganglia in chick embryo (12), provided a most valuable system for demonstrating the three main activities of NGF, i.e. (i) its vital trophic role during the early developmental stages, (ii) its property of enhancing differentiative processes such as neurite outgrowth, and (iii) of guiding the growing or regenerating neurites along its own concentration gradient $(43,44)$. These same cells offered an in-vivo model system to study the induction of enzymes involved in neurotransmitter synthesis (53) and were also instrumental in providing the first demonstration of NGF retrograde transport (54) and its role as a trophic messenger (55). If sensory and sympathetic cells played a key role in revealing these properties of NGF, chromaffin cells and their neoplastic counterpart, the clonal cell line PC12, became the model chosen for studying the capacity of NGF to modulate phenotypic expression and the molecular mechanism subserving this process (56). The phenotypic shift induced by NGF both in chromaffin $(57-58)$ and PC12 cells $(56,59)$, resulting in their neuronal differentiation accompanied by a plethora of chemical, ultrastructural and morphological changes, characteristic of the neuronal rather than glandular phenotype, is too well known to warrant a detailed description (50). These cells, moreover, uncovered the startling capacity of NGF to act as both a mitogenic (60) or antimotitic agent (56), even within the context of the same clonal cell line PC12 and of a mutated version of it (61). This, in turn, clearly pointed to the 'versatility' of NGF receptors and of their transduction machinery, whose message is evidently read and interpreted in different ways according to the cell type and previous cell history. The 'priming model' prospected to give a molecular account for the very fast and very slow onset of neurite outgrowth occurring, respectively, in sensory and sympathetic cells (24) on the one hand and PC12 cells on the other (50), is an excellent example of the contribution of these latter cells to studies on the mode of action of NGF.

Other examples of the wide and at the same time diversified NGF effects are illustrated by other sympatho-adrenal derivatives such as paraganglia, small intensely fluorescent cells (SIF) and carotid body cells (62-64). Particularly impressive evidence of the capacity of NGF to modulate phenotypic expression is the case of SIF cells which have been hypothesized as immediate precursors of both sympathetic and chromaffin cells. When these cells are cultured under appropriate conditions, they can be channelled towards the first or the second phenotype in media supplied with NGF or with dexamethasone $(63,64)$. Such an interplay, even in fully differentiated cells, between NGF and steroid hormones, is also indirectly suggested by in-vivo studies on the short adrenergic neurons which innervate, in both sexes, the genito-urinary systems (65).

In more recent years, two new populations came to the forefront of studies on NGF target cells: CNS neurons and cells originating from the hematopoietic system.

Small and large neuronal populations located in different brain areas have been shown to exhibit all properties and responses typical of sensory and sympathetic cells, such as: (i) the presence of specific receptors (66), (ii) retrograde transport of NGF (67), (iii) increased neurotransmitter synthesis with special reference to acetylcholine (68-70), and (iv) trophic response manifested as protection by exogenous NGF administration to selective noxious treatments or surgical transections otherwise leading to cell death $(71,72)$. A role for NGF in the development of as yet unidentified hypothalamic brain centers has been suggested by the finding that injections of affinity purified polyclonal antibodies against NGF in rat fetuses induce a severe postnatal neuroendocrine syndrome (29). The loop of an unquestionable NGF role in brain is completed by the demonstration that other nerve cells, especially those located in the hippocampus and cortical areas, manufacture large quantities of NGF mRNA and of NGF protein, thus closing the functional link between NGF-producing and NGF-responding cells (73-75). As prospected in the last section of this article, although the range of NGF action in the CNS is qualitatively comparable with that previously observed in peripheral neurons, the actual extent of the NGF role in brain is far from foreseeable due to the vast repertoire of possible responses from nerve cells in the CNS.

An analogous general consideration holds for the effect exerted by NGF on mast cells and possibly on other cells of the immune system. The increased in-vivo and in-vitro number of mast cells following NGF treatment $(76,77)$, as well as the effect of this growth factor on histamine release $(78-80)$, point to an unquestionable role in the physiology of these cells. It is not yet clear, however, whether such an effect is exerted through a generalized action on all mast cell precursors or through a sort of clonal selection mechanism. The more recent report of an NGF effect on other spleen cells such as mononuclear cells (81) and the existence of NGF receptors on thymocytes (82), clearly suggests that the NGF action extends also to cells belonging to a network of enormous functional significance. The role played by histamine as an immunomodulator and the obvious involvement of spleen cells in the immune response of the organism prospect new scenarios in which NGF may gain access, not through a back door, but through the main entrance.

\section{The I.D. card of NGF}

Sequencing of mouse submandibular gland NGF, achieved in 1971 (83), provided invaluable information not only on its primary structure but was recently instrumental in the preparation of synthetic oligonucleotides which resulted in the identification of NGF cDNA (84). The cloning which followed in rapid succession of mouse (84), human (85), bovine (86) and chick (87) genes, demonstrated their high degree of homology. The NGF gene, located in the human species on the proximal short arm of chromosome 1 (88), codes for a large polypeptide of 307 amino acid residues which, upon cleavage(s), gives origin to the 118 amino acid mature NGF subunit protein and, possibly, to other peptides of unknown function and with no sequence homology with presently identified proteins (84). NGF is a dimer made of two identical subunits held together by non-covalent bonds. The dimer can be isolated as such (89) or in the form of a complex consisting also of two other proteins, one with an esteropeptidase activity, probably involved in processing an NGF precursor, and the other with an as yet unknown function (90-92). While it remains to be established whether each NGF subunit is biologically active, it has been demonstrated that a covalently cross-linked form of the dimer maintains full activity $(91,92)$. Between the two well-identified molecular entities of NGF and of its coding gene, which can be visualized as the summit and the base of an iceberg, are several other possible intermediate forms of unknown nature and biological properties. Their identification would answer important questions such as: Are other biologically active peptides coded for by the NGF gene? 
What is the significance of different splicing in different cells of NGF mRNA (93)? Is the processing of pre-pro-NGF identical in all neuronal and non-neuronal cells or, as in other peptides (94), do alternate processing pathways result in the production of peptides endowed with different biological functions? Since the same peptides may undergo post-transcriptional or post-translational modification, the submerged areas of the NGF iceberg loom very large.

Studies on the immunological and biological relatedness of NGFs purified from different species, strongly support the hypothesis that the site(s) of interaction with their receptors has remained structurally more constant than is the case for other epitopes, probably free to mutate in view of their less fundamental biological functions (95).

\section{$N G F$, growth factor and oncogenes}

The discovery of NGF, soon followed by that of EGF, led to the biological identification of an ever-growing list of polypeptide growth factors (48). In the seventies, another apparently unrelated area of biology came to the forefront of research with the discovery of single gene products (oncogenes) causing transformation. PGF and oncogene research, pursued at first independently from each other, converged when homology between some oncogenes and growth factors or their receptors was shown by sequence analysis. Evidence is steadily increasing that excessive synthesis or an altered version of PGFs or of their receptors may result in transformation of recipient cells (95-98). More recently, the demonstration that the opposite is also true, namely, that certain oncogene products may induce differentiation of recipient cells, called attention to another facet of this intricate interplay between differentiative and transforming processes. The case of $\mathrm{H}-r a s$ and that of $\mathrm{v}-\mathrm{src}$, whose expression into PC12 cells $(99,100)$ result in mitotic arrest and neuronal differentiation comparable to those elicited by NGF, provide instances of a list most likely to grow. The obvious conclusion is that a given polypeptide growth factor, or intracellular proteins playing essential roles in the cell cycle or in differentiation of some cells, may exert markedly different actions in distinct cell types. In the case of NGF, one wonders if and how other actions are elicited by this versatile molecule. For instance, is an altered version of NGF or of its receptors capable of causing transformation of some recipient cells, as has been shown for other PGFs? If this is the case, could NGF in a modified version or its receptors be implicated in neoplasia in the central and peripheral nervous systems?

NGF in exocrine glands: a fortuitous presence or a biological function?

The early discovery that mouse submandibular glands synthesize and release into the saliva large quantities of NGF, that the synthesis of this protein molecule is under the control of testosterone and thyroxine $(101,102)$ and that the NGF protein content is 10-fold higher in male than in female mice, remained for about three decades a puzzling and unexplained finding. The conflicting but altogether negative attempts to reveal the presence of this molecule in the circulating blood $(49,51)$, and the lack of any adverse effects on sympathetic and sensory cells by removal of these glands, which deprived these rodents of such a large NGF source, militated against the hypothesis that salivary NGF gains access to their target cells. An alternative biological function for salivary NGF was first hypothesized by our group (103), and recently proved by us (104) and another investigator (105). We demonstrated that intraspecific fighting experimentally induced in adult male mice by $6-8$ weeks of social isolation, results in massive NGF release into the blood stream, an event prevented by previous sialoadenectomy. Since injections of NGF induce weight and size increase of the adrenal glands (105) and stimulate the synthesis of the catecholamine key enzyme, TH (106), we suggested that such a massive discharge into the blood circulation of endogenous salivary NGF may be instrumental in defense and/or offense mechanisms of vital significance for male mice that engage in intraspecific fighting among individuals of the same sex. In favor of this hypothesis is a recent report that aggressive behavior results in the release into the blood of another biologically active protein, renin, synthesized in the same tubular portions of these glands (107). The mechanism triggering this NGF release is not yet understood, nor whether other stations are activated and play a role in this specific stress syndrome.

As for the presence of large NGF sources in snake venom (18) and male genital organs $(108,109)$, they may be conceived as instances of bizarre evolutionary gene expression. Alternatively, in these cases NGF may subserve other functions which may somehow be linked with the poisonous action of snake venom, or the reproductive activity of the genital apparatus. In the case of snake venom, one can envisage the possibility that a highly specific neurotropic molecule such as NGF is utilized by reptiles as a carrier of other neurotoxins devoid of specific receptors in the central and peripheral nervous systems. For instance, enzymes such as phospholipases, phosphodiesterases and proteases of various nature, which by themselves may lack specific recognition sites in target cells, may exploit NGF as a carrier to gain access inside cells wherever there are specific NGF receptors. The widespread distribution of these specific molecules also in several non-neuronal cells could offer some toxins or enzymes a better access to their target organs.

In the reproductive tract, NGF could participate in fertilization mechanisms by cytoskeletal-mediated activation of spermatozoa locomotion much in the same way as in neurite outgrowth, or by favoring egg implantation, via inhibition of rejection through the immune system. This latter hypothesis is presently under investigation (Geraci, Cocchiara and Calissano) by assessing the effect of NGF on uterine mast cells which, through histamine release, are postulated to prevent the local immune reaction (110).

\section{Foreseeable approaches and predictions of the unpredictable}

The most obvious among the foreseeable approaches is the search for other NGF target cells, using the ever more sophisticated invivo and in-vitro techniques which have become available in these last decades to study the molecular to the supercellular levels. It was this multimodal approach which in recent years led to the discovery of NGF target cells in the CNS of lower and higher vertebrates and in cell lineages playing a role in the immune system. This list is likely to increase, as the search extends to other neuronal and non-neuronal cell populations. Furthermore, one should take into account the fact that some of these populations are receptive to NGF mainly during developmental stages of prenatal life. This was already demonstrated in sensory cells of avian and mammalian species $(49,51,52)$, and in cells lining the third ventricle in amphibian tadpoles (111) and prenatal and neonatal rodents (Aloe and Levi-Montalcini, unpublished observations). Likewise, the systematic screening of neuroendocrine and hematopoietic cell lines in in-vitro and in-vivo systems may reveal other as yet uncovered roles of this growth factor.

Another foreseeable approach now in progress in many laboratories, is the search and characterization of NGF-like factors active on other neuronal populations. These factors may be 
subdivided into two major classes: (i) those coded by the NGF gene itself but processed through alternate post-transcriptional or post-translational pathways leading to PGFs with a somewhat different structure and function; (ii) other proteins or peptides having the trophic, chemotactic and/or differentiative activity of NGF, but coded for by other genes.

The search and identification of factors belonging to the first group will take advantage of the techniques of molecular biology and immunology. These should provide valuable information on some of the still unexplored, submerged areas of the NGF iceberg, dealing with the processes of the NGF gene transcription or translation. Of particular importance would be the identification of the NGF sequence responsible for its binding to receptors which may presumably trigger a given cellular response (47). As previously surmised (95), this portion has possibly been better conserved than other parts of the molecule. Once identified, it will be feasible to introduce, in its synthetic counterpart, amino acid substitutions and/or chemical modifications and explore the biological potency of the newly manufactured peptide. This approach should not only provide invaluable information on the nature and properties of the NGF active center, but, hopefully, will result in the synthesis of peptides endowed with an activity even higher than that of NGF itself, so brilliantly achieved in the field of other biologically active peptides $(112,113)$.

Within this category of studies on NGF and its coding gene, one can conceive a strategy aimed at exploiting the property of non-neuronal cells in peripheral tissues and of neurons and satellites in the CNS to manufacture and release NGF by resorting to pharmacological agents that modify NGF gene expression or processing. The well-established findings that NGF synthesis is increased following transection of nerve fibers connecting NGF receptive nerve cells to their targets (114) or via hormonal action $(101,102)$, are an additional indication of the remarkable plasticity of the mechanisms controlling NGF gene expression. It is conceivable that this property might be modulated by pharmacological agents acting on the same path as those involved in regulation of the synthesis and release of NGF.

The search for neurotrophic factors coded by genes other than the NGF gene could take advantage, at least in its main lines, of the classical approach so successfully applied in the isolation and identification of NGF. Two main causes may explain why extensive work invested in this attempt has not been so successful in providing evidence for the existence of other PGFs activating different neuronal cell lines: (i) the lack of fast and reliable bioassays such as those developed for NGF and (ii) the failure to detect large sources of these factors comparable with those fortuitously discovered in early NGF studies. The realization of rapid, highly reliable bioassays can, however, now be achieved by resorting to the use of most stringent, chemically defined media, permitting survival and differentiation of only given cell types, upon addition to the medium of putative growth factors extracted from different sources and screened with the in-vitro bioassay for their potential specific growth enhancing activity. The problem of finding by sheer chance large sources of NGFlike peptides, such as those which played a key role in the discovery of NGF, can be solved by using the techniques of protein chemistry and recombinant DNA technology. This involves using a few micrograms of purified protein to decipher the sequence and as a result prepare the corresponding cDNAs to identify the gene of the PGF in question, and then express it in bacteria. Thus this replaces a search once guided by unpredictable strikes of luck, with a rational and systematic strategy.
Predictions of the unpredictable are encouraged by the same history of NGF which may be defined as a long sequence of unanticipated events which each time resulted in a new turn in the NGF unchartered route, and opened new vistas on an everchanging panorama. This trend, which became manifest from the very beginning and in fact alerted me to the existence of NGF, is perhaps the most attractive, even though elusive, trait of this thirty-five-year-long adventure. One can at present only predict where future developments are most likely to occur. The main causes of unpredictability of the findings reside in the intricacy of the new surroundings where NGF is moving - the CNS and the immune system - rather than in NGF itself. The enormous complexity of these two networks, which on the basis of recent findings are closely interrelated and influence each other through bidirectional signals $(115,116)$, opens endless possibilities for NGF activation of distinct repertoires of cells belonging to one or the other system. How many indirect effects can be elicited by direct NGF action on cholinergic, adrenergic and peptidergic neurons interlinked via fiber pathways and humoral channels or through short-distance diffusion? Likewise, how many effects could follow the simple histamine release by NGF-activated mast cells, considering the well established role of this amine as an immunomodulator or an immunosuppressor? These considerations hold also for the potential utilization of NGF in brain and immunosystem disorders. For instance, whenever cell death or specific neuronal populations may be linked to a decreased local availability of neutrophic factors, such as NGF, its exogenous supply or stimulation of its endogenous production via pharmacological agents may offer a promising approach to presently incurable diseases.

I shall end this account of the unfolding of the NGF story with a remark made more than a decade ago by Viktor Hamburger: '...the fact that this discovery, which grew out of a seemingly peripheral problem (peripheral in every sense of the word), has blazed so many new trails is its greatest contribution to neuroembryology' (117). Studies in this last decade have not only provided new strong evidence of the most important contributions of NGF in the field of neuroembryology, but brought to the fore its significance in the more general field of neuroscience and also prospect its role in that of the immune system.

I dedicate this article to Viktor Hamburger, who promoted and took part in this search, and to whom I am forever indebted for invaluable suggestions and generosity. Without him, the Nerve Growth Factor would never have come to our attention.

To my dear friends, Pietro Claissano and Luigi Aloe, I wish to express my deepest gratitude for their fundamental contributions. In this thirty-five-year-long investigation, a large number of colleagues, research associates and graduate students took part in this scientific adventure. I am particularly indebted and I very gratefully acknowledge the most important work performed by two of them: Drs Piero Angeletti and Vincenzo Bocchini. To Professor Carlos Chagas, for his generous hospitality in the Biophysic Institute of the University of Basil, and to Dr Hertha Meyer who helped me in devising the tissue culture bioassay of NGF, my warmest thanks.

\section{References}

1. Medawar,P.B. (1967) The Art of the Soluble. Methuen and Co. Ltd, pp. 106- 107 .

2. Harrison,R.G. (1935) Proc. R. Soc. Lond., Ser. B, 118, 155-196.

3. Hamburger,V. (1934) J. Exp. Zool., 449-494.

4. Tello,J.F. (1922) Trabajos Lab. Invest. Biol. Univ. Madrid, 21, 1-93.

5. Levi-Montalcini,R. (1964) Prog. Brain Res., 4, 1-29.

6. Levi-Montalcini,R. and Levi,G. (1943) Arch. Biol. Liège, 54, 183-206. 
7. Hamburger,V. and Levi-Montalcini,R. (1949) J. Exp. Zool., 111, 457-502.

8. Levi-Montalcini,R. (1949) J. Comp. Neurol., 91, 209-242.

9. Levi-Montalcini,R. (1950) J. Morphol., 86, 256-283.

10. Bueker,E.D. (1948) Anat. Rec., 102, 369-390.

11. Levi-Montalcini,R. and Hamburger,V. (1951) J. Exp. Zool., 116, 321-362.

12. Levi-Montalcini,R. (1952) Annu. N.Y. Acad. Sci., 55, 330-343.

13. Levi-Montalcini,R. and Hamburger,V. (1953) J. Exp. Zool., 123, 233-288.

14. Levi-Montalcini,R. (1975) In Worden,F.G., Swayzey,J.P. and Adelman,G. (eds), The Neurosciences: Paths of Discovery. MIT Press, pp. 245-265.

15. Levi-Montalcini,R., Meyer,H. and Hamburger,V. (1954) Cancer Res., 14, $49-57$.

16. Cohen,S., Levi-Montalcini,R. and Hamburger,V. (1954) Proc. Natl. Acad. Sci. USA, 40, 1014-1018.

17. Cohen,S. and Levi-Montalcini,R. (1956) Proc. Natl. Acad. Sci. USA, 42, 571-574.

18. Cohen,S. (1959) J. Biol. Chem., 234, 1129-1137.

19. Levi-Montalcini,R. and Cohen,S. (1956) Proc. Natl. Acad. Sci. USA, 42, 695-699.

20. Cohen,S. (1960) Proc. Natl. Acad. Sci. USA, 46, 302-311.

21. Levi-Montalcini, R. and Booker,B. (1960) Proc. Natl. Acad. Sci. USA, 46, 373-384.

22. Levi-Montalcini,R. and Booker,B. (1960) Proc. Natl. Acad. Sci. USA, 46, 384-391.

23. Levi-Montalcini,R. (1964) Science, 143, 105-110

24. Levi-Montalcini,R. (1966) The Harvey Lectures, 60, 217-219.

25. Levi-Montalcini,R. and Angeletti,P.U. (1966) Pharmacol. Rev., 18, 819-828.

26. Steiner,G. and Schönbaum,E. (eds) (1972) Immunosympathectomy. Elsevier Publishing Co., Amsterdam.

27. Levi-Montalcini,R. and Angeletti,P.U. (1963) Dev. Biol., 7, 653-659.

28. Levi-Montalcini,R., Aloe,L., Calissano,P. and Cozzari,C. (1980) Ist Meeting of the International Society for Developmental Neuroscience Strasbourg, Vol. 1, pp. 5.

29. Aloe,L., Cozzari,C., Calissano,P. and Levi-Montalcini,R. (1981) Nature, 291, 413-415.

30. Johnson,E.M., Gorin,P.D., Brandeis,L.D. and Pearson,J. (1980) Science, 210, 916-918.

31. Goedert,M., Otten,U., Schaefer,T., Schwab,M. and Thoenen,H. (1980) Brain Res., 201, 399-409.

32. Angeletti,P.U. and Levi-Montalcini,R. (1970) Proc. Natl. Acad. Sci. USA, 65, 114-121.

33. Calissano,P., Monaco,G., Menesini-Chen,M.G., Chen,J.S., Levi-Montalcini,R. (1976a) In Perry,S.W., Margret,A. and Adelstein,R.S. (eds), Contractile Systems in Non-muscle Tissue. Elsevier, Amsterdam, pp. 201-211.

34. Hendry,I.A. (1975) Brain Res., 90, 235-244.

35. Levi-Montalcini,R., Aloe,L., Mugnaini,E., Oesch,F. and Thoenen,H. (1975) Proc. Natl. Acad. Sci. USA, 72, 595-599.

36. Hendry,I.A. (1975) Brain Res., 94, 87-97.

37. Aloe,L., Mugnaini,E. and Levi-Montalcini,R. (1975) Arch. Ital. Biol., 113, $326-353$.

38. Stöckel,K., Paravicini,U. and Thoenen,H. (1974) Brain Res., 76, 413-421.

39. Hamburger,V., Brunso-Bechtold,V.J.K. and Yip,J.W. (1981) J. Neurosci. 1, 60-71.

40. Levi-Montalcini,R. (1976) Prog. Brain Res., 45, 235-258.

41. Menesini-Chen,M.L., Chen,J.S. and Levi-Montalcini,R. (1978) Arch. Ital. Biol., 116, 53-84.

42. Gundersen,R.W. and Barrett,J.N. (1979) Science, 206, 1079-1080.

43. Gunderson,R.W. and Barrett,J.N. (1980) J. Cell Biol., 87, 546-554.

44. Campenot,R.B. (1982) Dev. Biol., 93, 1-12.

45. Campenot,R.B. (1982) Dev. Biol., 93, 13-41.

46. Pfenninger,K.H. and Johnson,M.P. (1981) Proc. Natl. Acad. Sci. USA, 78, 7797-7800.

47. Calissano,P., Cattaneo,A., Aloe,L. and Levi-Montalcini,R. (1984) In Li,C.H. (ed.), Hormonal Proteins and Peptides. Academic Press, Vol. XII, pp. 1-56.

48. Bradshaw,R.A. (1978) Annu. Rev. Biochem., 47, 191-216.

49. Thoenen,H. and Barde,Y.A. (1980) Physiol. Rev., 60, 1284-1335.

50. Greene,L.A. and Shooter,E.M. (1980) Annu. Rev. Neurosci., 3, 353-402.

51. Calissano,P., Cattaneo,A., Biocca,S., Aloe,L., Mercanti,D. and LeviMontalcini,R. (1984) Exp. Cell Res., 154, 1-9.

52. Levi-Montalcini,R. and Calissano,P. (1986) Trends Neurosci., 9, 473-476.

53. Thoenen,H., Angeletti,P.U., Levi-Montalcini,R. and Kettler,R. (1971) Proc. Natl. Acad. Sci. USA, 68, 1598-1602.

54. Paravicini,U., Stoeckel,K. and Thoenen,H. (1975) Brain Res., 84, 279-291.

55. Johnson,E.M. and Yip,H.K. (1985) Nature, 314, 751-753.

56. Greene,L.A. and Tischler,A.S. (1976) Proc. Natl. Acad. Sci. USA, 73, $2424-2428$.
57. Unsicker,K., Krisch,B., Otten,U. and Thoenen,H. (1978) Proc. Natl. Acad. Sci. USA, 75, 3498-3502.

58. Aloe,L. and Levi-Montalcini,R. (1979) Proc. Natl. Acad. Sci. USA, 76, $1246-1250$.

59. Greene,L.A., Liem,R.K.H. and Shelanski,M.L. (1983) J. Cell Biol., 96, $76-83$.

60. Lillien,L.E. and Claude,P. (1985) Nature, 317, 632-634.

61. Burnstein,D.E. and Greene,L.A. (1982) Dev. Biol., 97, 477-482.

62. Levi-Montalcini,R. and Aloe,L. (1980) Adv. Biochem. Psychopharmacol., 25, 3-16.

63. Doupe,A.J., Patterson,P.H. and Landis,S.C. (1985) J. Neurosci., 5, $2143-2160$.

64. Doupe,A.J., Landis,S.C. and Patterson,P.H. (1985) J. Neurosci., 5, $2119-2142$

65. Owman,C. and Sjoberg,N.O. (1977) In James,V.H.T. (ed.), Proceedings of the 5th International Congress of Endocrinology. Excerpta Medica, Amsterdam, Vol. 1, pp. 205-209.

66. Szutowicz,A., Frazier,W.A. and Bradshaw,R.A. (1976) J. Biol. Chem., 251, 1516-1523.

67. Seiler,M. and Schwab,M. (1984) Brain Res., 30, 33-39.

68. Gnahn,H., Hefti,F., Heumann, R., Schwab,M.E. and Thoenen,H. (1983) Dev. Brain Res., 9, 45-52.

69. Hefti,F., Dravid,A. and Hartikka,J. (1984) Brain Res., 293, 305-311.

70. Mobley,W.C., Rutkowski,J.L., Tennekoon,G.I., Buchanan,K. and Johnston,M.V. (1985) Science, 229, 284-287.

71. Williams,L.R., Varon,S., Peterson,G.M., Wictorin,K., Fischer,W., Bjorklund,A. and Gage,F.H. (1986) Proc. Natl. Acad. Sci. USA, 83, 9231-9235.

72. Kromer,L.F. (1987) Science, 235, 214-216.

73. Korsching,S., Auburger,G., Heumann, R., Scott,J. and Thoenen,H. (1985) EMBO J., 4, 1389-1393.

74. Shelton,D.L. and Reichardt,L.F. (1986) Proc. Natl. Acad. Sci. USA, 83, $2714-2718$

75. Whittemore,S.R., Ebendal,T., Lärkfors,L., Olson,L., Seiger,A., Strömberg,I. and Persson,H. (1986) Proc. Natl. Acad. Sci. USA, 83, 817-821.

76. Aloe,L. and Levi-Montalcini,R. (1977) Brain Res., 133, 358-366.

77. Böhm,A. and Aloe,L. (1986) Acad. Naz. dei Lincei, 80, 1-6.

78. Bruni,A., Bigon,E., Boarato,E., Leon,A. and Toffano,G. (1982) FEBS Lett., 138, 190-192.

79. Sugiyama,K., Suzuki,Y. and Furuta,H. (1985) Arch. Oral. Biol., 30, 93-95.

80. Mazurek,N., Weskamp,G., Erne,P. and Otten,U. (1986) FEBS Lett., 198, $315-320$.

81. Thorpe,L.W., Werrbach-Perez,K. and Perez-Polo,J.R. (1986) $2^{\circ}$ International Workshop on Neuroimmunomodulation. Dubrovnik, Abstract, pp. 151.

82. Cattaneo,A. and Secher,D.S. (1987) Exp. Cell Res., in press.

83. Hogue-Angeletti,R. and Bradshaw,R.A. (1971) Proc. Natl. Acad. Sci. USA, 68, 2417-2420.

84. Scott,J., Selby,M., Urdea,M., Quiroga,M., Bell,G. and Rutter,W.J. (1983) Nature, 302, 538-540.

85. Ullrich,A., Gray,A., Berman,C. and Dull,T.J. (1983) Nature, 303, $821-823$.

86. Meier,R., Becker-Andre,M., Gotz,R., Heumann,R., Shaw,A. and Thoenen,H. (1986) EMBO J., 5, 1489-1493.

87. Ebendal,T., Larhammar,D. and Persson,H. (1986) EMBO J., 5 , $1483-1487$.

88. Francke,V., De Martinville,B., Coussens,L. and Ullrich,A. (1983) Science, 222, $1248-1250$

89. Bocchini,V. and Angeletti,P.U. (1969) Proc. Natl. Acad. Sci. USA, 64, 787-792.

90. Varon,S., Nomura,J. and Shooter,E.M. (1967) Biochemistry, 6, 2202-2210. 91. Varon,S., Nomura,J. and Shooter,E.M. (1968) Biochemistry, 7, 1296-1303.

92. Stach,R.W. and Shooter,E.M. (1974) J. Biol. Chem., 249, 6668-6674.

93. Edwards,R.H., Selby,M.J. and Rutter,W.J. (1986) Nature, 319, 784-787.

94. Eipper,B.A., Mains,R.E. and Herbert,E. (1986) Trends Neurosci., 100, 463-467.

95. Doolittle,R., Hunkapiller,M.W., Hood,L.E., DeVare,S.G., Robbins,K.L., Aaronson,S.A. and Antoniades,H.N. (1983) Science, 221, 275-276.

96. Downward,J., Yraden,Y., Mayes,E., Scace,G., Totty,N., Stockwell,P., Ullrich,A., Schlessinger,J. and Waterfield,M.D. (1984) Nature, 307, $521-527$.

97. Sherr,C.J., Rettenmier,C.W., Sacca,R., Roussel,M.F., Look,T.A. and Stanley,E.R. (1985) Cell, 41, 665-676.

98. Weinberger,C., Hollenberg,S.M., Rosenfeld,M.G. and Evans,R.M. (1985) Nature, 318, 670-673.

99. Bar-Sagi,D. and Feramisco,J.R. (1985) Cell, 42, 841-848.

100. Alema,S., Casalbore,P., Agostini,E. and Tatò,F. (1985) Nature, 316, 557-559. 


\section{R.Levi-Montalcini}

101. Levi-Montalcini,R. and Angeletti,P.U. (1964) In Sreebny,L.M. and Meyer,J. (eds), Salivary Glands and Their Secretions. Pergamon, Oxford, pp. 129-141.

102. Aloe,L. and Levi-Montalcini,R. (1980a) Exp. Cell Res., 125, 15-22.

103. Aloe,L., Cozzari,C. and Levi-Montalcini,R. (1985) Brain Res., 332, $259-265$.

104. Aloe,L., Alleva,E., Böhm,A. and Levi-Montalcini,R. (1986) Proc. Natl. Acad. Sci. USA, 83, 6184-6187.

105. Lakshmanan,J. (1986) Am. J. Physiol., 150, E386-391.

106. Otten,U., Schwab,M., Gagnon,C. and Thoenen,H. (1977) Brain Res., 133, 291-303.

107. Bing,J., Poulsen,K., Hackenthal,E., Rix,E. and Taugner,R. (1980) J. Histochem. Cytochem., 28, 874-880.

108. Harper,G.P., Barde,Y.A., Burnstock,G., Carstairs,J.R., Dennison,M.E., Suda,K. and Vernon,C.A. (1979) Nature, 279, 160-162.

109. Harper,G.P. and Thoenen,H. (1980) J. Neurochem., 34, 893-903.

110. Beer,D.J., Matloff,S.M., Rocklin,R.E. (1984) Adv. Immunol., 35, 209-215.

111. Levi-Montalcini,R. and Aloe,L. (1985) Proc. Natl. Acad. Sci. USA, 82 , $7111-7115$.

112. Kaiser,E.T. and Lawrence,D.S. (1984) Science, 226, 505-511.

113. Rajeshekhar,B. and Kaiser,E.T. (1986) J. Biol. Chem., 261, 13617-13623.

114. Ebendal,T., Olson,L., Seiger,A. and Hedlund,K.O. (1980) Nature, 286 , $25-28$.

115. Roszman,T.L., Jackson,J.C., Cross,R.J., Titus,M.J., Markesbery,W.R. and Brooks,W.H. (1985) J. Immunol., 135, 769s-772.

116. Hall,N.R., McGillis,J.P., Spangelo,B.L. and Goldstein,A.L. (1985) J. Immunol., 135, 806-811.

117. Hamburger,V. (1975) Perspect Biol. and Med., 18, 162-178. 